\title{
The effects of grazing on the spatial pattern of elm (Ulmus pumila L.) in the sparse woodland steppe of Horqin Sandy Land in northeastern China
}

\author{
M. Zhang ${ }^{1, *}$, J. Wu ${ }^{1, *}$, and Y. Tang ${ }^{1}$ \\ ${ }^{1}$ School of Life Sciences, Liaoning University, Shenyang, China \\ *These authors contributed equally to this work.
}

Correspondence to: Y. Tang (tangyi@lnu.edu.cn)

Received: 29 October 2015 - Published in Solid Earth Discuss.: 27 November 2015

Revised: 29 March 2016 - Accepted: 4 April 2016 - Published: 19 April 2016

\begin{abstract}
The aim of this study was to explore the effects of grazing on the formation of the spatial pattern of elm growth in a sparse woodland steppe. We used a point pattern method to analyze the elm trees within different diameter at breast height $(\mathrm{DBH})$ classes in both grazed and fenced plots, which were established in Horqin Sandy Land of northeastern China. The results showed that, in the grazed plot, the distances where transformation between random and clustered patterns occurred in class $1(10 \mathrm{~cm} \leq \mathrm{DBH} \leq 15 \mathrm{~cm})$ and class $2(15 \mathrm{~cm}<\mathrm{DBH} \leq 20 \mathrm{~cm})$ were 2.27 and $2.37 \mathrm{~m}$, respectively. Meanwhile, in the fenced plot, the distances between random and aggregated patterns that occurred in classes 1, 2 and 3 (DBH > $20 \mathrm{~cm}$ ) were $3.13,3.13$ and $7.85 \mathrm{~m}$, respectively. In the fenced plot, at distances larger than $67.72 \mathrm{~m}$ there was a negative association between classes 1 and 2, which was also the case between classes 2 and 3 and between classes 1 and 3 for distances greater than 104.09 and $128.54 \mathrm{~m}$, respectively. Meanwhile, negative associations occurred only at distances larger than $29.38 \mathrm{~m}$ in the grazed plot. These findings suggest that grazing reduced the competition intensity between elm trees; and therefore, grazing management could be an effective strategy used to regulate the elm population in the degraded sandy land of northern China.
\end{abstract}

\section{Introduction}

Vegetation and soil are key parts of the Earth system that sustain societies with services, goods and resources (Berendse et al., 2015; Brevik et al., 2015). The grazing impact on soils and vegetation causes some ecosystems to be affected by land degradation processes (Cerdà and Lavee, 1999; Mekuria et al., 2013; Tarhouni et al., 2015). Desertification, one of the most important types of land degradation, occurs widely in the world, especially in China (Izzo et al., 2013; Jafari et al., 2013; Salvati et al., 2013; Wang et al., 2013; Bisaro et al., 2014; Fleskens and Stringer, 2014).

In arid and semiarid land of northern China, grazing is considered as a key driving force behind desertification, as it affects vegetation and soil (Deregibus et al., 1994; Kraaij and Ward, 2006; Wang et al., 2015). Therefore, exploring the effects of grazing on vegetation, especially original vegetation, is helpful for understanding the desertification process.

Elm (Ulmus pumila L.) trees are the main constituents in forming sparse woodland steppes, which is considered the original vegetation type and is the focus of the vegetation restoration efforts in Horqin Sandy Land, one of the largest sandy lands in China (Yu and Chen, 2007; Tang et al., 2014). Sparse elm steppes play an important role in promoting vegetation restoration (Jiang et al., 2003), reducing wind erosion (Jin et al., 2009) and increasing carbon storage (Zeng et al., 2009).

The effect of grazing on elm trees has raised great attention recently (Dulamsuren et al., 2009). Previous reports have documented an increase in seed production in grazed pastureland (Tang et al., 2014) and a reduction in elm popula- 
tion density (Li et al., 2003). Few studies have focused on the spatial pattern of elm distribution in these areas. Plant spatial patterns provide fundamental information for understanding the regeneration processes of species and for inferring mechanisms resulting in species' coexistence in communities (Leps and Kindlmann, 1987; Ward et al., 1996). For instance, Hubbell (1979) studied the trees' dispersal in a deciduous forest to explain the high species diversity in tropical forests. Janzen (1970) predicts that the spatial pattern of seedlings' recruitment is influenced by a density- or distance-dependent factor, such as host-specific predators or pathogens. Therefore, exploring the effects of grazing on the spatial pattern of elm in a sparse woodland steppe is helpful for explaining the formation of spatial structure in a sparse elm steppe and is also important for protecting biodiversity and promoting vegetation restoration.

To our knowledge, few studies have been carried out on the spatial pattern of elm distribution. This is primarily due to the large-scale experimental region required to explore sparse space structure. In the 1980s, a 13 ha area was considered a large-scale experiment (Hubbell, 1979); yet, in recent years 20-25 ha is now the norm ( $\mathrm{Li}$ et al., 2009). The increasing standard of area in large-scale experiments reflects the growing appreciation of spatial scale dependence. Spatial scale dependence reflects how the plant spatial pattern differs for each measured scale (Picard et al., 2009). In sparse forests, the average distance between elm trees is larger than what is found for plants in a rainforest. Thus, a large-scale experimental region is necessary to explore effects of grazing on spatial pattern of elm in sparse woodland steppes. This study provided experimental evidence of grazing effects on the spatial pattern of sparse elm steppes in a large-scale region. The main aims of this study were (1) to study the effects of grazing on the spatial pattern of elm in sparse woodland steppes, (2) to investigate the change in spatial patterns at a large scale and (3) to identify the associations of spatial pattern between different scaled groups. Our findings could contribute to the understanding of the formation of the spatial pattern of elm population in a sparse woodland steppe.

\section{Materials and methods}

\subsection{Study area}

The study was conducted in the Wulanaodu region in Horqin Sandy Land in northeastern China $\left(119^{\circ} 39^{\prime}-120^{\circ} 02^{\prime} \mathrm{E}\right.$, $42^{\circ} 29^{\prime}-43^{\circ} 06^{\prime} \mathrm{N} ; 480 \mathrm{~m}$ a.s.1.). In the region, the seasonal grazing regime, which prohibits grazing from May to September, has prevailed in recent years. The study area belongs to a semiarid climate. Mean minimum temperature is $-14.0^{\circ} \mathrm{C}$ in the coldest month (January) and $23.0^{\circ} \mathrm{C}$ in the warmest month (July). The mean annual precipitation is $340 \mathrm{~mm}, 70 \%$ of which falls between June and August (Li et al., 2006; Yan and Liu, 2010). Annual mean wind velocity is
$4.4 \mathrm{~m} \mathrm{~s}^{-1}$ and the number of gale days $\left(>16 \mathrm{~m} \mathrm{~s}^{-1}\right)$ is $21-80$. The windy season is from March to May, and the growing season begins in late April and ends in late September. The prevalent wind direction is northwest, and the second prevalent wind direction is southwest. The landscape of the study area is characterized by a mosaic of active sand dunes, stabilized dunes and dune slacks (Cao et al., 2011). Soil of the sand dunes and the dune slacks was aeolian sandy soil and meadow soil, respectively (Liu et al., 2012).

Two permanent plots, one of 44.2 ha $(650 \mathrm{~m} \times 680 \mathrm{~m})$ that was fenced in 1998, and another of $10.5 \mathrm{ha}(300 \mathrm{~m} \times 350 \mathrm{~m})$ that was grazed, were included in the test area. The slopes in the two regions were $3-5^{\circ}$ on average. The fenced plot was almost the same as the grazed plot in terms of soil physical and chemical characteristics and microtopography before it was fenced. For example, pH, soil bulk density, total N, and total $\mathrm{P}$ were $7.75-7.87,1.55-1.58 \mathrm{~g} \mathrm{~m}^{-3}, 0.045-0.051$ and $0.29-0.54 \mathrm{~g} \mathrm{~kg}^{-1}$ respectively in the fenced plot (Han, 2012). In the grazed plot, $\mathrm{pH}$, soil bulk density, total $\mathrm{N}$, and total $\mathrm{P}$ were $7.7,1.65-1.72 \mathrm{~g} \mathrm{~m}^{-3}, 0.046-0.080$ and $0.26-$ $0.30 \mathrm{~g} \mathrm{~kg}^{-1}$ respectively (Cao, 1990). The species included elm and the following other species: Caragana microphylla Lam., Setaria viridis (Linn.) Beauv. subsp. viridis, Bassia dasyphylla (Fisch. et Mey.) O. Kuntze, Chenopodium acuminatum Willd., Chenopodium glaucum Linn., Chenopodium aristatum Linn., Lespedeza davurica (Laxm.) Schindl., and Pennisetum centrasiaticum Tzvel.

\subsection{Data collection and analysis}

Within the two plots mentioned above, the diameter at breast height $(\mathrm{DBH})$ was measured and the number of trees with $\mathrm{DBH} \geq 10 \mathrm{~cm}$ was recorded. As superior competitive ability requires a relatively large plant body size, we thought that $10 \mathrm{~cm}$ DBH is enough to avoid the potential effects of interspecific competition between elm and other species in the study area. According to the $\mathrm{DBH}$, elm trees were divided into three groups: class $1(10 \mathrm{~cm} \leq \mathrm{DBH} \leq 15 \mathrm{~cm})$, class 2 $(15 \mathrm{~cm}<\mathrm{DBH} \leq 20 \mathrm{~cm})$ and class $3(\mathrm{DBH}>20 \mathrm{~cm})$ (Li et al., 2011).

To estimate the spatial pattern of elm trees, coordinates of trees with $\mathrm{DBH} \geq 10 \mathrm{~cm}$ were recorded using GPS (Global Position System; the accuracy is $0.5 \mathrm{~m}$ at a maximum). The GPS coordinates were transformed into a relative $x-y$ axis (Fig. 1). Point patterns of trees were analyzed using Ripley's $L(r)$ function (Gray and He, 2009). $L(r)=0$ for completely spatial randomness (CSR), $L(r)>0$ for clustered pattern, while $L(r)<0$ for uniform pattern. To assess the significance level of non-CSR, Monte Carlo simulation $(n=99)$ was used.

The second-order bivariate estimator of the Ripley's $L$ function was used for detecting associations between the three classes mentioned above. The $L$ functions and Monte Carlo simulations were calculated using the spatstat package 

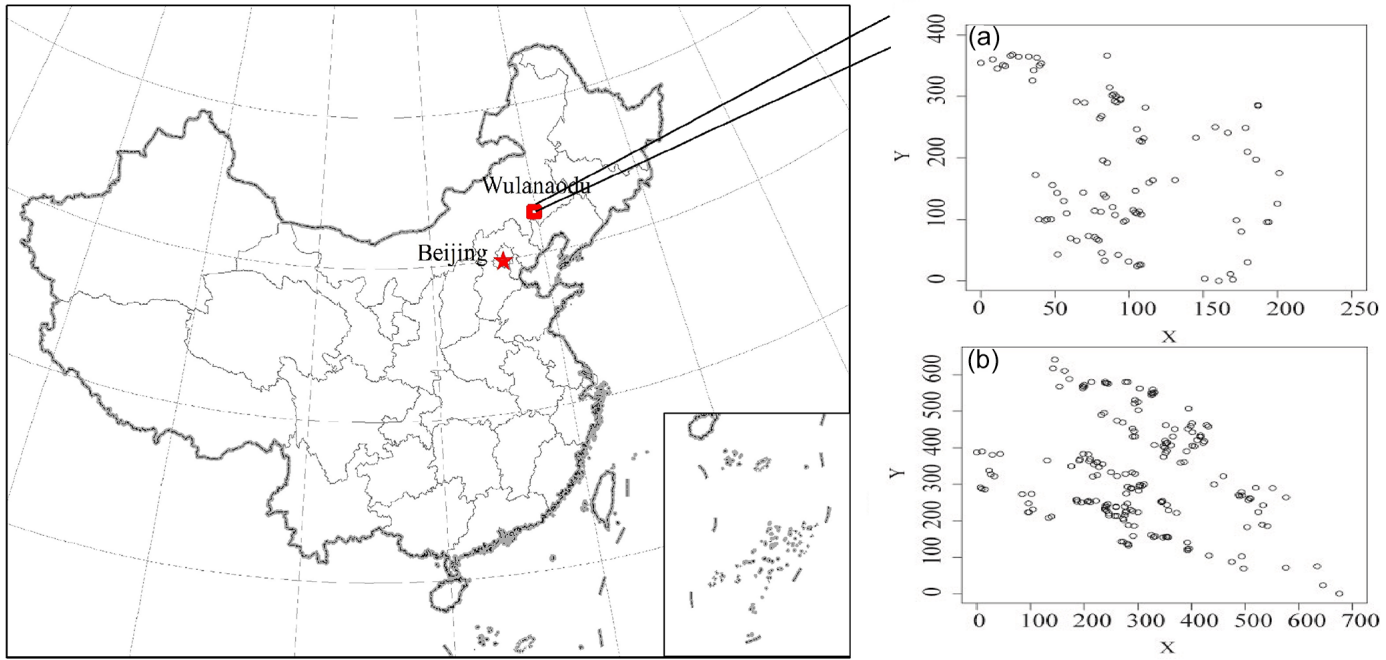

Figure 1. The location of the study area and relative coordinates of elm trees in grazed plots (a) and fenced plots (b).

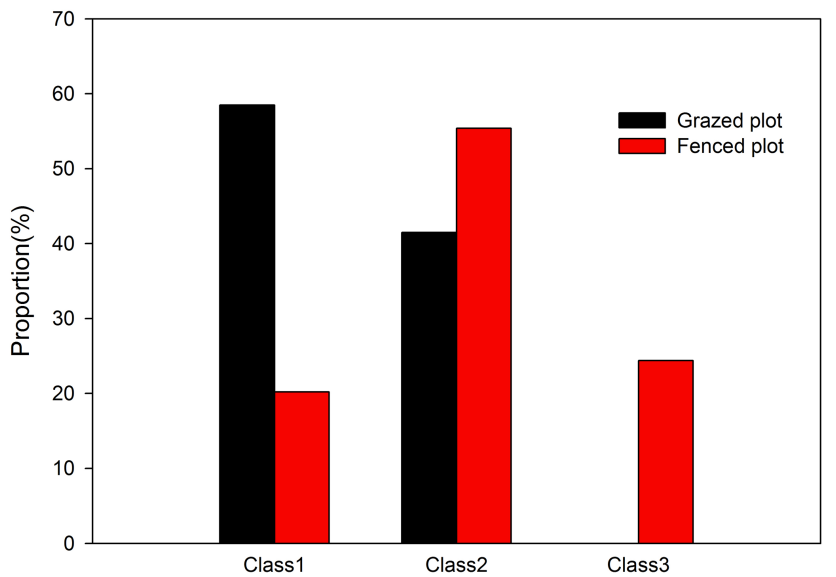

Figure 2. The proportion of elm tree classes in grazed and fenced plots. Class 1 consists of elm trees with $10 \mathrm{~cm} \leq \mathrm{DBH} \leq 15 \mathrm{~cm}$; class 2 elm trees with $15 \mathrm{~cm} \leq \mathrm{DBH} \leq 20 \mathrm{~cm}$; class 3 elm trees with $\mathrm{DBH}>20 \mathrm{~cm}$.

in the R statistical programming software (Baddeley et al., 2005).

\section{Results}

\subsection{Density of elm trees in grazed and fenced plots}

Within the grazed plot, the density of elm trees $(\mathrm{DBH}>10 \mathrm{~cm})$ was 8.95 individual ha ${ }^{-1}$. The proportion of trees in classes 1 and 2 was 58.5 and $41.5 \%$, respectively. The elm trees in class 3 were not found in the grazed plot (Fig. 2). Meanwhile, within the fenced plot, the density of elm trees $(\mathrm{DBH}>10 \mathrm{~cm})$ was 4.37 individual ha ${ }^{-1}$. The
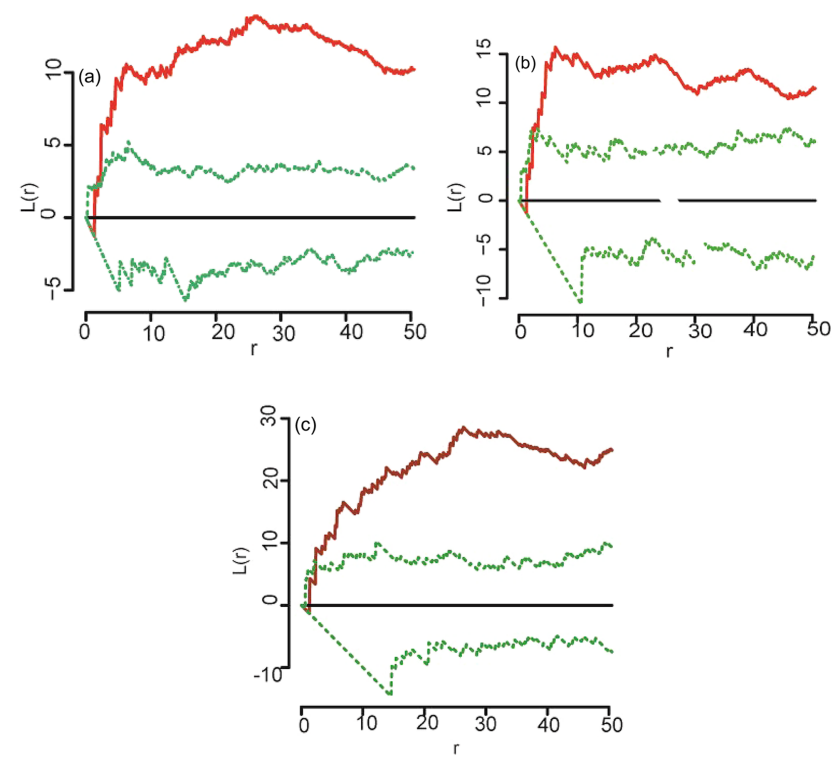

Figure 3. Ripley's $L(r)$ functions and Monte Carlo intervals for elm trees in different classes. Observed patterns (red color, straight line) fell above, below and within $95 \%$ Monte Carlo intervals (green color, dashed line). The spatial pattern of all elm trees with $\mathrm{DBH} \geq 10 \mathrm{~cm}$ in the grazed plot was shown in (a). The spatial patterns of elm with two classes in the grazed plot were shown in (b) $10 \mathrm{~cm} \leq \mathrm{DBH} \leq 15 \mathrm{~cm}$ and (c) $15 \mathrm{~cm}<\mathrm{DBH} \leq 20 \mathrm{~cm}$.

proportion of trees in classes 1,2 and 3 was 20.2, 55.4 and $24.4 \%$, respectively (Fig. 2).

\subsection{Spatial patterns of elm trees in grazed and fenced plots}

Within the grazed plot, the random pattern of elm distribution transformed into a clustered pattern at a distance of $1.87 \mathrm{~m}$ 
(Fig. 3a). For elm trees in class 1, the transformation of a random to a clustered pattern occurred at a distance of $2.27 \mathrm{~m}$ (Fig. 3b). When the distance was over $3.27 \mathrm{~m}$, a random spatial pattern appeared for trees in class 2 , and then an aggregated pattern was present (Fig. 3c).

The random pattern transformed into the clustered pattern at the distance of $1.58 \mathrm{~m}$ in the fenced plot (Fig. 4a). The intensity of aggregation was positively correlated to an increase in distance. For elm trees in class 1, the transformation of the random pattern to the clustered pattern appeared at the distance of $3.13 \mathrm{~m}$ (Fig. 4b). If the distance was over $3.13 \mathrm{~m}$, a random pattern appeared for trees in class 2 and then the clustered pattern occurred (Fig. 4c). For trees in class $3(\mathrm{DBH}>20 \mathrm{~cm})$, the random pattern appeared over a distance of $7.85 \mathrm{~m}$ and the clustered pattern occurred within greater distances (Fig. 4d).

\subsection{Associations between elm groups in grazed and fenced plots}

Within the grazed plot, trees designated in classes 1 and 2 had distribution patterns that were positively associated within a range from 4.54 to $6.11 \mathrm{~m}$ but had a negative association when the distance was larger than $29.38 \mathrm{~m}$. The association correlation did not show a significant effect with a distance of zero (Fig. 5a).

The negative and positive associations appeared alternately within the fenced plot. For elm trees in classes 1 and 2, a positive association was evident between them within a range of 3.78 to $35.12 \mathrm{~m}$, and a negative association observed when in a range of a distance larger than $67.72 \mathrm{~m}$ (Fig. 5b). The association of elm trees in classes 1 and 3 was positive at a distance of $8.16-20.07 \mathrm{~m}$, and negative at distance larger than $128.54 \mathrm{~m}$ (Fig. 5c). Meanwhile, the association of elm trees in classes 2 and 3 was negative at larger distances greater than $104.09 \mathrm{~m}$ (Fig. 5d).

\section{Discussion}

According to our results, the transformation between random and clustered patterns that were observed in the grazed plot between classes 1 and 2 occurred over a distance of 2.27 and $2.37 \mathrm{~m}$, respectively. Meanwhile, in the fenced plot, the transformation between these patterns for in classes 1, 2 and $3 \mathrm{oc}-$ curred over distances of $3.13,3.13$ and $7.85 \mathrm{~m}$, respectively. This suggested that the distance between random and clustered patterns was larger in the fenced plot than that in the grazed plot.

The initial spatial pattern of elm population is formed during the seed rain stage, and results in a clustered pattern (Yang et al., 2012, 2013). In conjunction with the growth of the plant population, the spatial pattern of all trees (not just elm trees) shows a shift from a clustered pattern to one of uniform distribution (Weiner et al., 2001; Stoll and Bergius,
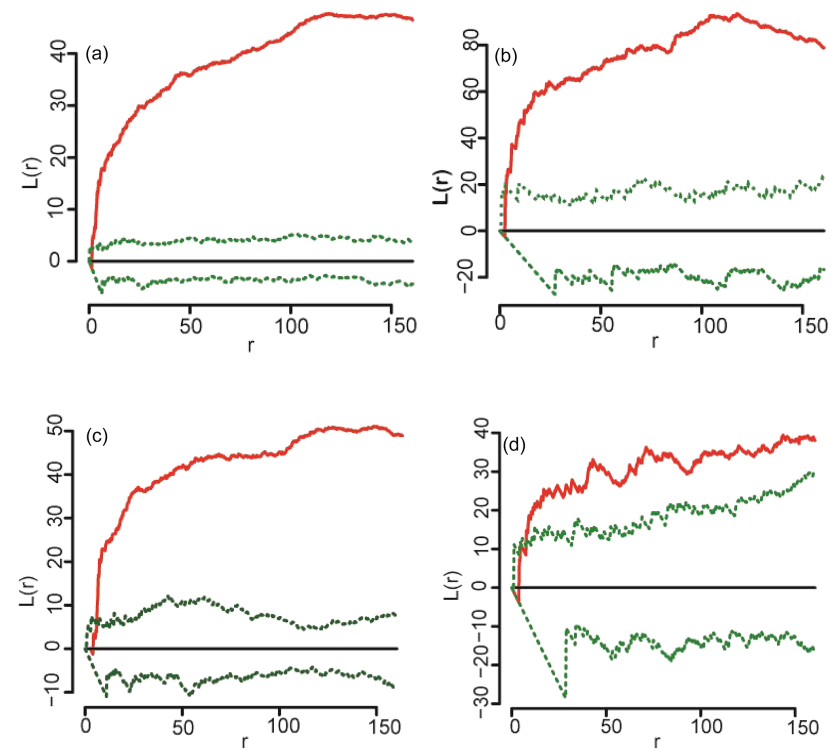

Figure 4. Ripley's $L(r)$ functions and Monte Carlo intervals for elm trees in different classes. Observed patterns (red color, straight line) fell above, below and within 95\% Monte Carlo intervals (green color, dashed line). The spatial pattern of all elm trees with $\mathrm{DBH} \geq 10 \mathrm{~cm}$ in the fenced plot was shown in (a). The spatial patterns of elm with three classes in the fenced plot were shown in (b) $10 \mathrm{~cm} \leq \mathrm{DBH} \leq 15 \mathrm{~cm}$, (c) $15 \mathrm{~cm}<\mathrm{DBH} \leq 20 \mathrm{~cm}$ and (d) $\mathrm{DBH}>20 \mathrm{~cm}$.

2005; Picard et al., 2009). Previously, Barbour (1973) proposed that, statistically, the most likely dispersal of shrubs is uniform in pattern, which is largely determined by the competition for resources (Toft and Fraizer, 2003). However, an important consideration is the fact that the transformation from a clustered to a uniform pattern is a process, and midway during this process, the spatial pattern appears random. For example, Barot et al. (1999) found that the spatial pattern of adult savanna palm trees had a random pattern or loosely clustered pattern, compared with that of the clustered pattern of young trees. If competition led to the change in spatial pattern, i.e., transformation from a clustered pattern to a uniform pattern, then the larger distance between the clustered and uniform pattern suggests greater competition intensity. Thus, grazing may reduce the competition intensity in the sparse elm steppe, given the shorter distance between clustered and uniform patterns noted here.

Our results suggest that grazing regulates the spatial pattern of the sparse woodland steppe, and by doing so, represents one of the underlying mechanisms that govern the formation of plant spatial pattern. Here, the distance between the clustered and uniform patterns within grazed and fenced plots was 1.87 and $1.58 \mathrm{~m}$, respectively. This was consistent with work by Lin et al. (2010), who found that grazing altered the fine-scale $(<2 \mathrm{~m})$ processes in a desert steppe in Inner Mongolia, China. However, in our study the increase in 

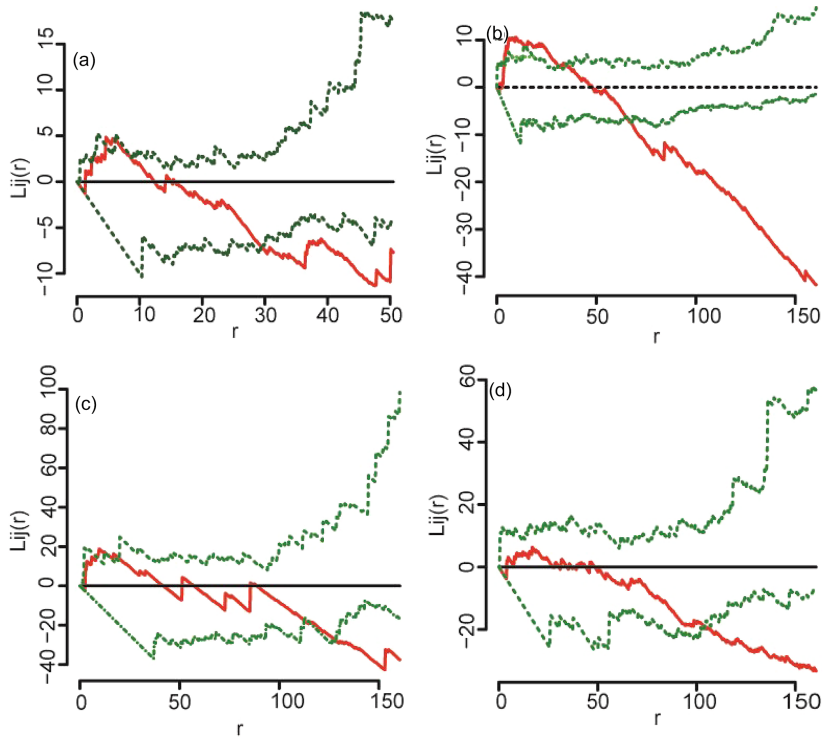

Figure 5. Associations between different classes. Observed patterns (red color, straight line) fallen below and above $95 \%$ Monte Carlo intervals (green color, dashed line) stood for the significant difference. The associations between class $1(10 \mathrm{~cm} \leq \mathrm{DBH} \leq 15 \mathrm{~cm})$ and class $2(15 \mathrm{~cm}<\mathrm{DBH} \leq 20 \mathrm{~cm})$ in the grazed plot was shown in (a). The associations between class $1(10 \mathrm{~cm} \leq \mathrm{DBH} \leq 15 \mathrm{~cm})$ and class $2(15 \mathrm{~cm}<\mathrm{DBH} \leq 20 \mathrm{~cm})$ in the fenced plot was shown in (b). The associations between class $1(10 \mathrm{~cm} \leq \mathrm{DBH} \leq 15 \mathrm{~cm})$ and class $3(\mathrm{DBH}>20 \mathrm{~cm})$ was shown in (c). And the associations between class $2(15 \mathrm{~cm}<\mathrm{DBH} \leq 20 \mathrm{~cm})$ and class $3(\mathrm{DBH}>20 \mathrm{~cm})$ was shown in (d).

distance between the random and clustered pattern occurred in an orderly way, rather than the clustered patterns appearing on a fine scale and random patterns occurring on a relatively large scale as reported previously (Niu et al., 2008; Ren and Zhao, 2013).

In the fenced plot, negative associations appeared between classes 1 and 2 in distances larger than $67.72 \mathrm{~m}$, between classes 2 and 3 in distances larger than $104.09 \mathrm{~m}$ and between classes 1 and 3 in distances larger than $128.54 \mathrm{~m}$. Thus, as the diameter increases, negative associations of elm trees groups tend to appear in larger distances. Individuals with large sizes need more resources to live and the competition intensity between them may be more severe than that between individuals with smaller sizes (Weiner et al., 2001). Therefore, competition intensity is related to the distance where negative association appears and when negative associations appear in the larger distances, which results in more competition intensity. In the grazed plot, the negative association occurred in a distance larger than $29.38 \mathrm{~m}$, which is far less than that in the fenced plot. Thus, the competition intensity was reduced in the grazed plot, suggesting that grazing may be a useful factor to regulate population structure and promote vegetation restoration in Horqin Sandy Land. In Horqin Sandy Land, a lack of resources, especially water supply, limits the perfor- mance of individuals and hampers the recruitment in populations (Chesson et al., 2004). Importantly, these findings offer an alternative to the prevailing view that suggests that enclosure management is an effective measure to promote vegetation restoration (Jiang et al., 2003).

The co-occurrence of intra-specific and inter-specific competition is common in nature (Packer and Clay, 2000; Condit et al., 2002) and it is difficult to separate the effects of these on spatial distribution. The inter-specific competition is not considered here, which is mainly due to asymmetric competition between elm trees and other plants in the sparse elm steppe. In the sparse woodland steppe, the size of elm trees is far larger than shrubs and herbs, and allows them to have a competitive advantage over smaller plants (Frecketon and Watkinson, 2001). Thus, we believed that the effects of intra-specific competition played a more important role than inter-specific competition in regulating the spatial pattern of elm trees (Schwinning and Weiner, 1998). The communities with single dominant species, as observed in this study, are more suitable for detecting specific competition.

\section{Conclusions}

Our study suggests that grazing regulates the spatial pattern of elm trees in a sandy land, and this is likely due to the reduction of intra-specific competition between elm trees. Given this, we believe that grazing management would favor the optimization of the spatial pattern in elm populations through its role in reducing intra-specific competition. In particular, grazing management would be an effective strategy to regulate growth distribution of the elm population in the degraded sandy land of northern China.

Acknowledgements. This work was supported by the National Basic Research Program of China (no. 2013CB429905), National Nature Science Foundation of China (no. 41201052) and Program for Liaoning Excellent Talents in University (no. LJQ2013003). We would also like to thank Angela Scott at the McMaster University for her assistance with English language and grammatical editing of the manuscript.

Edited by: P. Pereira 


\section{References}

Baddeley, A., Turner, R., Moller, J., and Hazelton, M.: Residual analysis for spatial point processes. J Royal Stat. Soc. B, 67, 617651, 2005.

Barbour, M. G.: Desert dogma reexamined root-shoot productivity and plant spacing, Am. Midl. Nat., 89, 41-57, 1973.

Barot, S., Gignoux, J., and Menaut, J. C.: Demography of a savanna palm tree: predictions from comprehensive spatial pattern analyses, Ecology, 80, 1987-2005, 1999.

Berendse, F., van Ruijven, J., Jongejans, E., and Keesstra, S. D.: Loss of plant species diversity reduces soil erosion resistance of embankments that are crucial for the safety of human societies in low-lying areas, Ecosystems, 18, 881-888, 2015.

Bisaro, A., Kirk, M., Zdruli, P., and Zimmermann, W.: Global drivers setting desertification research priorities: insights from a stakeholder consultation forum, Land Degrad. Dev., 25, 5-16, 2014.

Brevik, E. C., Cerdà, A., Mataix-Solera, J., Pereg, L., Quinton, J. N., Six, J., and Van Oost, K.: The interdisciplinary nature of Soil, Soil, 1, 117-129, 2015.

Cao, C. Y., Jiang, S. Y., Ying, Z., Zhang, F. X., and Han, X. S.: Spatial variability of soil nutrients and microbiological properties after the establishment of leguminous shrub Caragana microphylla Lam. plantation on sand dune in the Horqin Sandy Land of Northeast China, Ecol. Eng., 37, 1467-1475, 2011.

Cao, X. S.: Integrated management of sand-drift activities and drought in Eastern Inner Mongolia, Science Press, Beijing, China, 275-276, 1990.

Cerdà, A. and Lavee, H.:The effect of grazing on soil and water losses under arid and mediterranean climates, Implications for desertification, Pirineos, 153-154, 159-174, 1999.

Chesson, P., Gebauer, R. L. E., Schwinning, S., Huntly, N., Wiegand, K., Ernest, M. S. K., Sher, A., Novoplansky, A., and Weltzin, J. F.: Resource pulses, species interactions, and diversity maintenance in arid and semi-arid environments, Oecologia, 141, 236-253. 2004.

Condit, R., Pitman, N., Leigh, E. G., Chave, J., Terborgh, J., Foster, R. B., Nunez, P., Aguilar, S., Valencia, R., Villa, G., MullerLandau, H. C., Losos, E., and Hubbell, S. P.: Beta-diversity in tropical forest trees, Science, 295, 666-669, 2002.

Deregibus, V. A., Casal, J. J., Jacabo, E. J., Gibson, D., Kauffman, M., and Rodriguez, A. M.: Evidence that heavy grazing may promote the germination of Lolium multiflorum seeds via phytochrome-mediated perception of high red/far-red ratios, Funct. Ecol., 8, 536-542, 1994.

Dulamsuren, C., Hauck, M., Nyambayar, S., Bader, M., Osokhjargal, D., Oyungerel, S., and Leuschner, C.: Performance of Siberian elm (Ulmus pumila) on steppe slopes of the northern Mongolian mountain taiga: drought stress and herbivory in mature trees, Environ. Exp. Bot., 161, 18-24, 2009.

Fleskens, L. and Stringer, L. C.: Land management and policy responses to mitigate desertification and land degradation, Land Degrad. Dev., 25, 1-4, 2014.

Frecketon, R. P. and Watkinson, A. R.: Asymmetric competition between plant species, Funct. Ecol., 15, 615-623, 2001.

Gray, L. and He, F.: Spatial point-pattern analysis for detecting density-dependent competition in a boreal chronosequence of Alberta, Forest Ecol. Manag., 259, 98-106, 2009.
Han, W. J.:Physio-ecological adaptability of Artemisia sphaerocephalla in aerial seeding area of Horqin Sandy Land, Inner Mongolia Normal University, 19-20, 2012.

Hubbell, S. P.: Tree dispersion, abundance, and diversity in a tropical dry forest, Science, 203, 1299-1309, 1979.

Izzo, M., Araujo, N., Aucelli, P. P. C., Maratea, A., and Sánchez, A.: Land sensitivity to desertification in the dominican republic: AN adaptation of the ESA methodology, Land Degrad. Dev., 24, 486-498, 2013.

Jafari, R. and Bakhshandehmehr, L.: Quantitative mapping and assessment of environmentally sensitive areas to in central iran, Land Degrad. Dev., 27, 108-119, doi:10.1002/ldr.2227, 2013.

Janzen, D. H.: Herbivores and the number of tree species in tropical forests, Am. Nat., 104, 501-258, 1970.

Jiang, D. M., Liu, Z. M., Cao, C. Y., and Kou, Z. W.: Desertification and Ecological Restoration of Keerqin Sandy Land, China Enviromental Science Press, Beijing, 2003.

Jin, H.M, Sun, O. J., Luo, Z. K., and Liu, J.: Dynamics of soil respiration in sparse Ulmus pumila woodland under semi-arid climate, Ecol. Res., 24, 731-739, 2009.

Kraaij, T. and Ward, D.: Effects of rain, nitrogen, fire and grazing on tree recruitment and early survival in bush-encroached savanna, South Africa, Plant Ecol., 186, 235-246, 2006.

Leps, J. and Kindlmann, P.: Models of the development of spatial pattern of an even-aged plant population over time, Ecol. Model., 39,45-57, 1987.

Li, G. T., Zhao, R. G., Yu, X. X., and Yue, Y. J.: Life history characteristics of natural Elm populations in Hunshandak sandland, J. Arid Land Resour. Environ., 25, 161-165, 2011.

Li, L., Huang, Z. L., Ye, W. H., Cao, H. L., Wei, S. G., Wang, Z. G., Liao, J. Y., Sun, I. F., Ma, K. P., and He, F. L.: Spatial distributions of tree species in a subtropical forest of China, Oikos, 118, 495-502, 2009.

Li, X. H., Li, X. L., Jiang, D. M., and Liu, Z. M.: Germination strategies and patterns of annual species in the temperate semiarid region of China, Arid Land Res. Manag., 20, 195-207, 2006.

Li, Y. G., Jiang, G. M., Gao, L. M., Niu, S. L., Liu, M. Z., and Yu, S. L.: Impact of human disturbance on Elms-Motte-Veldt in Hunshandak Sand Land, Acta Phytoecol. Sin., 27, 829-834, 2003.

Lin, Y., Hong, M., Han, G. D., Zhao, M. L., Bai, Y. F., and Chang, S. X.: Grazing intensity affected spatial patterns of vegetation and soil fertility in a desert steppe, Agr. Ecosyst. Environ., 138, 282-292, 2010.

Liu, B., Liu, Z. M., and Wang, L. X.: The colonization of active sand dunes by rhizomatous plants through vegetative propagation and its role in vegetation restoration, Ecol. Eng., 44, 343-347, 2012.

Mekuria, W. and Aynekulu, E.: Exclosure land management for restoration of the soils in degrade communal grazing lands in Northern Ethiopia, Land Degrad. Dev., 24, 528-538, 2013.

Niu, L. L., Yu, X. X., Yue, Y. J.: Spatial patterns of different ageclass individuals in Pinus tabulaeformis forest in Songshan Nature Reserve of Beijing, China, Chin. J Appl. Ecol., 19, 14141418, 2008.

Packer, A. and Clay, K.: Soil pathogens and spatial patterns of seedling mortality in a temperate tree, Nature, 404, 278-281, 2000 . 
Picard, N., Bar-Hen, A. M. F., and Chadoeuf, J.: Understanding the dynamics of an undisturbed tropical rain forest from the spatial pattern of trees, J. Ecol., 97, 97-108, 2009.

Ren, H. and Zhao, C. Z.: Spatial pattern and competition relationship of Stellera chamaejasme and Aneurolepidium dasystachys population in degraded alpine grassland, Acta Ecol. Sin., 33, 435-442, 2013.

Salvati, L., Zitti, M., and Perini, L.: Fifty years on: Long-term patterns of land sensitivity to desertification in italy, Land Degrad. Dev., 27, 97-107, doi:10.1002/ldr.2226, 2013.

Schwinning, S. and Weiner, J.: Mechanisms determining the degree of size asymmetry in competition among plants, Oecologia, 113, 447-455, 1998.

Stoll, P. and Bergius, E.: Pattern and process: competition causes regular spacing of individuals within plant populations, J. Ecol., 93, 395-403, 2005.

Tang, Y., Jiang, D. M., and Lv, X. T.: Effects of exclosure management on elm (Ulmus Pumila) recruitment in Horqin Sandy Land, Northeastern China, Arid Land Res. Manag., 28, 109-117, 2014.

Tarhouni, M., Ben Hmida, W., and Neffati, M.: Long-Term Changes in Plant Life Forms as a Consequence of Grazing Exclusion under Arid Climatic Conditions. Land Degrad. Dev., 27, 479-489, doi:10.1002/ldr.2369, 2015.

Toft, C. A. and Fraizer, T.: Spatial dispersion and density dependence in a perennial desert shrub (Chrysothamnus nauseosus: Asteraceae), Ecol. Monogr., 73, 605-624, 2003.

Wang, T., Xue, X., Zhou, L., and Guo, J.: Combating aeolian desertification in Northern China. Land Degrad. Dev., 26, 118-132, 2015 .
Wang, X., Wang, G., Lang, L., Hua, T., and Wang, H.: Aeolian transport and sandy desertification in semiarid china: a wind tunnel approach, Land Degrad. Dev., 24, 605-612, 2013.

Ward, J. S., Parker, G. R., and Ferrandino, F. J.: Long-term spatial dynamics in an old-growth deciduous forest, Forest Ecol. Manag, 83, 189-202, 1996.

Weiner, J., Stoll, P., Muller-Landau, H., and Jasentuliyana, A.: The effects of density, spatial pattern, and competitive symmetry on size variation in simulated plant populations, Am. Nat., 158, 438-450, 2001.

Yan, S. G. and Liu, Z. M.: Effects of dune stabilization on plant diversity of interdune wetlands in the northeastern Inner Mongolia, China, Land Degrad. Dev., 21, 51-60, 2010.

Yang, Y. F., Bai, Y. P., and Li, J. D.: Spatial difference and regularity of seed dispersal of Ulmus macrocarpa in Horqin Sandy Land, China, Chin. J Plant Ecol., 36, 747-753, 2012.

Yang, Y. F., Bai, Y. P., and Li, J. D.: Seed dispersal and seedling recruitment of Ulmus pumila woodland in the Keerqin Sandy Land, China, Acta Ecol. Sin., 33, 374-381, 2013.

Yu, S. L. and Chen, H. W.: Characteristics and formation causes of temperate sparse forest grassland ecosystem in InnerMongolia Plateau, Chin. J. Ecol., 26, 549-554, 2007.

Zeng, D. H., Hu, Y. L., Chang, S. X., and Fan, Z. P.: Land cover change effects on soil chemical and biological q properties after planting Mongolian pine (Pinus sylvestris var. mongolica) in sandy lands in Kerqin, northeastern China, Plant Soil, 317, 121133, 2009. 